\title{
Exploration on Application of Scaffolding Teaching Method in English translation Teaching
}

\author{
Jing Li, Liwei Miao \\ Harbin University Of Science And Technology, Harbin, 150080, China
}

Keywords: English teaching, English translation, Scaffolding teaching, Teaching innovation.

\begin{abstract}
Scaffolding teaching method is an important method in constructivism teaching system. As a modern scientific teaching mode, scaffolding teaching method has been proven to be an effective teaching method through dual test of theory and practice. It has been widely applied in modern teaching, in English translation teaching, scaffolding teaching method can help students construct language learning system and achieve effective promotion of learning efficiency.
\end{abstract}

\section{Concept of scaffolding teaching method}

Under constructivism teaching mode, scaffolding teaching method is a scientific teaching method with good teaching effect. From the perspective of concept, scaffolding teaching method means in the teaching process, teachers set rational learning objective for students through scientific course design, and guide students to explore through knowledge introduction layer by layer and to finally grasp problem-solving ability. The name of scaffolding teaching mode stems from the building field. In the building process, the scaffolding is first used as the auxiliary equipment to complete the main part of the building. When the main part is finished, then the auxiliary scaffolding will be removed to achieve the independent existence of the building.[1] The application of scaffolding teaching method in teaching process is also such process. The scaffolding first guides students to solve problems. When they form their own knowledge hierarchy, the scaffolding will be removed to make students grasp problem-solving ability.

Scaffolding teaching method comes from "the Zone of Proximal Development" theory of famous psychologist Vygotsky. Such scientific teaching mode aims to help educatees construct their own knowledge hierarchy, grasp problem-solving ability, narrow the gap between educatees and the problems to be solved and achieve ability promotion.

Under scaffolding teaching mode, students' learning process is not one-way passive reception, but a two-way interaction process. In learning process, students continuously enhance their problem-solving ability and explore the scheme and approach to solve problems. During carrying out scaffolding teaching, teachers do not directly impart knowledge to students, but first deconstruct complex knowledge and guide students to start from small problems and finally construct the whole knowledge system frame so as to reach the purpose of solving problems.

\section{Internal link between English translation teaching and scaffolding teaching}

ODEI teaching objective pursued by modern English translation happens to hold the same view with internal teaching principle of scaffolding teaching method. In modern English translation teaching, ODEI teaching objective should be achieved. In other words, teachers should guide students to observe, finally make their translation ability improve and help them construct their own knowledge hierarchy through effective discussion, expansion and imitation. Hence, the application of scaffolding teaching method in English translation teaching has strong pertinence and effectiveness.

Scaffolding teaching is different traditional teaching mode. In traditional translation teaching process, the teacher dominates the class, and imparts translation skills and knowledge to students. Scaffolding teaching mode requires the teacher to respect students' individual differences and 
expression. The teacher should guide students to enhance their translation ability with their knowledge reserve and form their own translation thought and system. To apply scaffolding teaching method in English translation teaching, teachers should motivate students' initiative and guide them to explore actively.

Compared with traditional teaching, English teachers should enhance course design in English translation teaching when scaffolding teaching method is applied. In other words, students should help students design rational "learning scaffolding" according to different features of students and choose appropriate teaching contents for them ${ }^{[2]}$. During teaching objective design and content selection, students should set the course content within students' scope of ability according to students' mastery condition and knowledge complexity so as to motivate their learning potential, learning confidence and interest to the largest extent.

Compared with traditional teaching mode, scaffolding teaching method puts forward higher requirements for English translation teachers. Scaffolding teaching method requires teachers to make preparations before class. The traditional mode requires teachers to own high ability in the teaching process, while scaffolding teaching method requires teachers to preset learning problems and steps through scientific and rational course design before class. To gain good teaching effect of scaffolding teaching method, teachers must grasp the teaching content macroscopically and carefully know students' conditions.

\section{Strategies to apply scaffolding teaching method in English translation}

\section{To discover students' "Zone of Proximal Development"}

To carry out scaffolding teaching, teachers should find out students' "Zone of Proximal Development" through observing and understanding them so as to improve teaching pertinence and effectiveness. Before the course, teachers should enhance top-level design and make the teaching objective clear. For example, during translating science and technology articles, teachers should stress translation principles and subordinate clause translation method in the course design. The specific noun details may not be included in the key teaching content. Meanwhile, targeted course design should be made according to different features of students. Teachers should provide students with suitable teaching content through accurately grasping their ability and course difficulty.

For example, when translating "Studies of the Weddell seal in the laboratory have described the physiological mechanisms that allow the seal to cope with the extreme oxygen deprivation that Occurs during its longest dives, which can extend 500 meters below the ocean's surface and last for over 70 minutes", the teacher should guide students. This article about somatic functions of Weddell seal has strong scientificity, so it is hard to translate it. But many professional terms are not the key points of translation. In the translation teaching process, the teacher should put the key point on sentence pattern comprehension and the differences in English- Chinese sentence pattern expression, and let students find out the expression differences through contrastive analysis and pay special attention to subject changes and sentence structure. Meanwhile, the changes in the part of speech exist in the translation process, which is also a key problem in scaffolding teaching. In the translation process, teachers also should actively gather students' feedbacks, know their learning difficulties and blind points and further highlight the pertinence in teaching instruction and summarization.

\section{To help students set up "expectation" scaffolding}

When applying scaffolding teaching method in English translation teaching, teachers should strengthen course design, help students establish appropriate "expectation" scaffolding and design rational and scientific learning objectives for students through carefully grasping students' situations, defectively analyzing translation contents and carefully decomposing the contents. In teaching process, teachers should find out students' "Zone of Proximal Development" according to teaching contents, design targeted teaching problems through creating teaching situations, and guide students to go deep in the course content and to explore effective methods and ways to solve problems. For instance, before translation teaching, teachers should intensify students' consciousness of problems, 
first preset problems and let students think over them, "Which changes will happen in English-Chinese translation at the lexical level?" "Whether will English part of speech and quantity change in the translation process?" These preset problems can remind students to focus on the key points so as to improve English translation learning pertinence and effectiveness[3].

Under scaffolding teaching mode, teachers are required to put more energy on before-class, find out students' "Zone of Proximal Development" through "presetting" scaffolding, make the distance between students and knowledge close, discover teaching difficulties and key and achieve effective improvement of English translation teaching quality and level.

During "presetting" scaffolding, English translation teachers should follow teaching laws, design problems from the easier to the more advanced, make students go deep into English translation knowledge hierarchy gradually and solve problems one by one through scientific guidance, and finally help them construct their own knowledge hierarchy and realize effective improvement of English translation ability.

\section{To organically combine independent study with collaborative learning}

When scaffolding teaching method is applied in translation teaching, independent study with collaborative learning should be combined. Cultivating students' ability of independent study is an important goal of scaffolding teaching. In translation teaching process, teachers should motivate students' learning interest through course design, and guide them to think independently, to explore problem solving methods and ways and to really grasp knowledge application methods. For instance, in translation training, the teacher should ask students to answer questions instead of directly giving the answers and actively guide students to think independently[4]. Scaffolding teaching method aims to cultivate students' ability of independent study.

With the development of educational theory and teaching practice, cooperative learning has been proven to be an effective teaching mode and it has been widely applied in modern courses. When scaffolding teaching method is applied in English translation teaching, teachers should be good at applying cooperative teaching mode, decompose difficult and complex problems, assign the problems to different students according to their features and then guide them to finish translation tasks through cooperation. In this way, students can learn from others' strong points to offset their weakness. Meanwhile, students can improve their teamwork ability.

For example, in English translation teaching, the culture contained in many English paragraphs presents certain richness and tacitness. Due to the limit of personal knowledge reserve and comprehension, it is hard for students to complete translation independently. So, teachers may group students rationally, and let the students with different knowledge background cooperate and solve the problems through decomposing the complex translation tasks. It is also an effective way to improve translation teaching quality and promote students' translation ability.

\section{To enhance course summarization and evaluation}

When scaffolding teaching method is applied in English translation teaching, teachers should be good at course summarization and evaluation. When scaffolding teaching method is applied, knowledge is scattered. After the course ends, teachers must summarize, evaluate in time, help students construct knowledge hierarchy and intensify their independent translation ability. In the summarizing process, teachers should deeply expound the translation theory, and organically combine translation problems to guide them to explore translation methods and skills so as to achieve improvement of translation ability.

For example, the part of speech of English word often changes during translating English works. Teachers should introduce common word transformation method and amplification method in English translation, and gather the scattered knowledge through theory teaching. In this way, there is specific translation case and theory method summarization. The whole classroom presents three-dimensional characteristic, and can be more easily accepted by students. Meanwhile, students' independent translation ability can improve to the largest extent ${ }^{[5]}$. 
Meanwhile, teachers should enhance guidance pertinence in classroom summarization. Except the general problems, teachers also should fully consider different features of students, explain for them with pertinence and guide the difficult points so as to achieve knowledge digestion and achieve good teaching effect. In the translation process, teachers should fully explain the knowledge students do not understand. In the specific teaching process, many students cannot grasp the essence of translation, because they lack the ability of context analysis. Thus, in the process of classroom comment and summarization, teachers should combine contextual analysis method to let students consider problems from the perspective of social culture and system, compare differences between English culture and Chinese culture and find out the differences so as to make the translation close to target language.

\section{Conclusion}

In conclusion, the application of scaffolding teaching method in translation teaching can effectively enhance teaching pertinence and effectiveness, help students construct their own English translation system and enhance English translation ability. In teaching process, the application of scaffolding teaching method has high requirements for teachers. Teachers need to grasp scientific teaching mode and method and improve professional technical level to better provide translation teaching guidance for students and practically improve English translation teaching level.

\section{References}

[1] Xiao Lin, Ren Zhipeng, Application of scaffolding teaching method in English translation teaching, Education Exploration, 2013(11):60-61.

[2] Chen Jingying, Study on application of scaffolding teaching method in English translation teaching, Journal of Lanzhou Institute of Education, 2014(9):128-129.

[3] Lai Xiaofeng, Exploration on college English translation teaching based on scaffolding teaching method, Journal of Hubei University of Science and Technology, 2015,35(4):120-122.

[4] Liu Chong, Research on the Value of Applying Scaffolding Teaching Method to English Translation Teaching, The Science Education Article Collects, 2014(22):149-149,155.

[5] Liu Zhixuan, On scaffolding teaching method in Business English translation course of higher vocational schools, English Square (II), 2015(6):99-100. 